\title{
The Challenge of Maintaining Successful Aging at 87 Years Old: The Octabaix Study Two-Year Follow-Up
}

\author{
Francesc Formiga, ${ }^{1,3}$ Assumpta Ferrer, ${ }^{2}$ Jesus Alburquerque,, Manuel Fernández-Quevedo, ${ }^{1}$ Cristina Royo, \\ and Ramón Pujol ${ }^{1,3}$ on behalf of the Octabaix Study Members*
}

\begin{abstract}
Preserving physical and cognitive function is crucial to successful aging. The objective of this study is to determine how many 87-year-old community-dwelling subjects continued to age successfully, according to a definition using a quantitative approach, and to assess the predictive value of certain factors evaluated 2 years previously. A total of 162 participants were assessed. Sociodemographic variables, the Barthel Index (BI), the Spanish version of the Mini-Mental State Examination (MEC), the Mini Nutritional Assessment (MNA), the Charlson Index, the Gait Rating Scale, social risk, quality of life, prevalent chronic diseases, and chronic drug prescription were collected. All subjects with scores over 90 points on the BI and above 23 points on the MEC were compared with the rest of the participants. A multiple regression analysis was performed. With the selected criteria, $90(61.6 \%)$ community-dwelling subjects continued to age successfully. The multiple logistic regression analysis showed that the following were significantly associated with continued successful aging: A higher level of studies ( $p<0.02$, odds ratio [OR] 3.223, 95\% confidence interval [CI] 1.158-8.975), better MEC scores $(p<0.01$, OR 1.204, 95\% CI 1.046-1.386) and Tinetti gait scale scores ( $p<0.01$, OR 1.433, 95\% CI 1.013-2.027), and fewer chronic drug prescriptions $(p<0.001$, OR $0.768,95 \%$ CI $0.655-0.899)$. In conclusion, more than half of the individuals continued to age successfully. In subjects aged 87 years, the factors associated with continued successful aging were longer schooling, better cognition scores, lower risk of falls, and fewer chronic drug prescriptions at baseline evaluation.
\end{abstract}

\section{Introduction}

N DEVEloped Countries, the average life span of men and women continues to increase, and consequently the oldest old is a growing population segment. ${ }^{1}$ To reduce the burden and enhance the benefits associated with an aging population, research responses to the factors that favor any decrease in age-disease disability are very important. The goal is to reach old age with the maximum health status. In the last few decades, the concept of successful aging has gained importance in medical sciences. As a result, a variety of definitions encompassing physical, functional, psychological, and social health have been reported. ${ }^{2-6}$
Previously, we evaluated a nonagenarian cohort in our area (the Nonasantfeliu study) $)^{7,8}$ to assess possible differences between subjects who were aging successfully. Successful aging was defined by good functional and cognitive status and living in the community, among other factors. We concluded that male nonagenarians with low co-morbidity are probably more successful than female nonagenarians with high co-morbidity. ${ }^{7}$

In a subsequent study of the Octabaix cohort (328 subjects aged 85 years), we found that almost half of the participants were aging successfully (49.3\%), according to the quantitative definition chosen. Subjects aged 85 years with low comorbidity and a minor risk of malnutrition and falls were associated with more successful aging. ${ }^{9}$

\footnotetext{
${ }^{1}$ Geriatric Unit, Internal Medicine Service, Hospital Universitari de Bellvitge, L'Hospitalet de Llobregat, Barcelona, Spain.

${ }^{2}$ Centro de Atención Primaria "El Plà" CAP, Sant Feliu de Llobregat, Barcelona, Spain.

${ }^{3}$ Bellvitge Biomedical Research Institute, IDIBELL, L'Hospitalet de Llobregat, Barcelona, Spain.

${ }^{4}$ ICASS-Residència Feixa Llarga, L’Hospitalet de Llobregat, Barcelona.

*Members of the Octabaix Study: J. Almeda (Unitat de Suport a la Recerca de Costa de Ponent, IDIAP J Gol); T. Badia (ABS Martorell Urbano); A. Lobato (ABS Sant Andreu de la Barca); C. Fernández (CAP Rambla); A. Ferrer (CAP El Pla); F. Formiga (UFISS de Geriatría, Servicio de Medicina Interna, Hospital Universitari de Bellvitge); A. Gil (ABS Sant Andreu de la Barca); M.J. Megido (ABS Just Oliveras); G. Padrós (Laboratori Clínic L'Hospitalet-Cornellà); M. Sarró (CAP Florida Nord); and A. Tobella (ABS Martorell Rural).
} 
The aim of the current study was to evaluate the proportion of subjects who were classified as aging successfully at the beginning of the Octabaix study (out of a cohort of community-living subjects aged 85 years at baseline) that maintained their higher functional and cognitive status and were still living in the community after a follow-up period of 24 months. We also aimed to identity some predictors of continued successful aging.

\section{Methods}

The Octabaix study is a prospective cohort study. The initial participants were 328 community-dwelling inhabitants born in 1924 (85 years old at the time of inclusion) and registered with one of seven primary care teams in the geographical area of Baix Llobregat, Barcelona, Spain. The sample is described in more detail elsewhere. ${ }^{9,10}$ In brief, every old inhabitant was interviewed at their home or their health center by a geriatric-trained research team. The institutional ethics committee approved the study. All patients or the caregivers of cognitively impaired subjects gave their written informed consent before enrollment. We assessed all patients without exclusion criteria of health or cognitive status. A geriatric assessment and sociodemographic data (gender, marital status, place of residence, studies, and living alone) were included in the interview. Functional status, cognitive status, nutritional status, social risk, gait, and falls were assessed by instruments currently used in geriatric practice.

Functional status was measured using the Barthel Index $(\mathrm{BI})^{11}$ for the basic activities of daily living (ADL). The total BI score ranges from 0 to 100 points (from help needed to independent in all activities). Cognitive function was measured by the Spanish version of the Mini-Mental State Examination (MEC), ${ }^{12}$ which has a total score of 35 (a score below or equal to 23 indicates cognitive impairment). Nutritional status was assessed using the Mini Nutritional Assessment (MNA). ${ }^{13}$ The MNA score is based on 18 items covering four component subscores. The score obtained (maximum 30 points) enabled the elderly people to be classified into three categories: 24-30, well-nourished; 17-23.5, at risk of malnutrition; and $<17$, malnourished. Gait was evaluated with the Gait Rating Scale from the Tinetti Performance-Oriented Mobility Assessment. This scale consists of seven components ${ }^{14}$ and provides a final score that ranges from 0 to 12 , with a higher score indicating better gait performance. A fall was defined as any incident in which the patient ends up on the ground or at a lower level against his/her will (and not due to an intentional movement). ${ }^{15}$ Patients and/or caregivers were asked about any falls in the last year. The Gijon scale was used for the social assessment. ${ }^{16}$ This scale is scored on a maximum of 24 points. Social risk scores are those between 10 and 14, and social problems exist with scores $>15$. Quality of life was assessed using the Quality of Life Test (EuroQol-5D) with the visual analog scale (EQ-VAS) of perceived health from 0 to 100: 0 represents the worst state of health imaginable and 100 the best. ${ }^{17}$

The Charlson score (CS) was used to measure overall comorbidity. ${ }^{18}$ It ranges from 0 to a theoretical maximum of 33, depending on the presence of certain diseases with assigned values. Data on some cardiovascular risk factors were collected, including hypertension, diabetes mellitus, and dyslipidemia. For most diseases, we determined prevalence by reviewing the data included in the general practice records: Ischemic cardiomyopathy, heart failure, stroke, chronic obstructive lung disease, cancer, and atrial fibrillation were reported. The total number of chronic drug prescriptions and blood test results was collected.

\section{Procedure}

We defined successfully aging subjects as those who were noninstitutionalized and had scores of 91 or higher on the BI and 24 or higher on the MEC. We had already used these criteria to assess the oldest old population in our area. ${ }^{7-9}$ We found that 162 of the total Octabaix cohort of 328 subjects $(49 \%)$ were aging successfully at baseline. ${ }^{9}$ After a 2-year follow-up, we had data on the functional, cognitive, and living status of 146 of these 162 (90\%) successfully aging individuals. Sixteen subjects declined to participate (no differences in gender and BI and MEC scores at baseline from the rest of the subjects who continued with the study were present). In the present study, we reevaluated the successfully aging subjects at baseline to check if they still had this status. We considered that subjects who had died or had been institutionalized had not attained the objective.

\section{Data analysis}

Normally distributed continuous variables are reported as mean \pm standard deviation (SD). Categorical variables are reported as proportions. Normal or nonnormal distributions of continuous variables were assessed using the KolmogorovSmirnov test. The Student $t$-test was used to compare continuous variables, with a previous Levene test for equality of variances, whereas either the chi-squared statistic or Fisher exact test was used to compare categorical or dichotomous variables. A logistic regression analysis was performed to determine the variables associated with successful aging. The variables entered into the regression model were gender, all the variables with significant differences in the bivariate analysis (level of studies, MEC, MNA, Tinetti gait scale, number of falls, previous diagnosis of atrial fibrillation, and number of chronic drug prescriptions), as well as functional status (BI) and co-morbidity (Charlson Index). An adjusted odds ratio (OR) with a 95\% confidence interval (CI) was used. To evaluate the model generated, we tested goodness of fit using the Hosmer-Lemeshow test and we also computed the pseudo- $\mathrm{R}^{2}$ of Cox-Snell. The results were considered significant when $p<0.05$. All analyses were performed using SPSS 15.0 statistical software (SPSS Inc., Chicago, IL).

\section{Results}

The final sample comprised 146 subjects aged 87 at the time of the evaluation. There were 82 women (56.2\%) and 64 men. Fifty subjects (34.2\%) lived alone. Regarding marital status, 73 (50\%) were married, $66(45.2 \%)$ widowed, and 7 $(4.8 \%)$ unmarried. Thirty-six $(24.7 \%)$ had a university degree or had reached high school, and the remaining 110 (75.3\%) had primary studies or did not have any studies at all.

\section{Geriatric assessment}

The mean values of the scales used in the geriatric assessment at baseline were as follows: BI $98.6 \pm 2.2$ for basic 
ADL and MEC $30.6 \pm 2.2$ in relation with cognition. The mean of the MNA for malnutrition risk was $26.2 \pm 2.5$, with most subjects scoring well-nourished $(77 \%)$ and no malnourished patients. The mean of the other geriatric assessment scales were Tinetti Gait Scale $8.2 \pm 1.2$ for fall risk and finally $9.1 \pm 2.2$ on the Gijon test for social risk. The mean of the EuroQol-5D-EQ-VAS was $68.3 \pm 18$.

\section{Co-morbidity evaluation}

The mean Charlson Index was $1.05 \pm 1.3$. In relation to major cardiovascular risk, hypertension was found in 114 $(78.1 \%)$ subjects, diabetes in $18(12.3 \%)$ and dyslipidemia in $778(52.7 \%)$. Seven subjects had previous clinical histories of ischemic cardiomyopathy $(4.8 \%), 15$ heart failure $(10.3 \%)$, 8 chronic obstructive pulmonary disease (5.5\%), 16 atrial fibrillation (11\%), 19 cancer (13\%), and 17 stroke (11.6\%). Patients were taking an average of $5.3 \pm 3$ chronic drugs, whereas 126 patients $(86 \%)$ were treated with three or more drugs. The mean number of falls recorded in the previous year was $0.38 \pm 0.7$ falls per subject.

\section{Successful aging at 2-year follow-up}

The mean value of BI at the 24-month assessment was BI $92.6 \pm 15.1$, with $94(64.6 \%)$ subjects maintaining BI scores above 90. In relation to cognition, the mean MEC score after the follow-up period was 27.5 \pm 8.1 , with $115(78.8 \%)$ individuals having MEC values higher than 23 points. With the selected quantitative criteria including function and cognition, $90(61.6 \%)$ community-dwelling subjects continued to age successfully. The main reasons for losing successful status in the remaining 56 subjects were: 39 (69.6\%) lost on the BI Index score, 18 (32.1\%) lost on the MEC (the drops were both recorded in 14 subjects), and finally 13 (23.2\%) died. Acquired disability was associated with institutionalization in six subjects.

Table 1 shows the differences between the two groups. In the group aged 87 years with successful aging, there was a higher level of studies and better scores on the MEC, MNA, and Tinetti gait scale. In the nonsuccessful aging group, there was a higher number of falls in the previous year, a high percentage of subjects with a diagnosis of atrial fibrillation, and a higher number of chronic drug prescriptions.

Using multiple logistic regression analysis, successfully aging subjects were significantly associated with a continued successful aging status, a higher level of studies, better scores on the MEC and the Tinetti gait scale, and a lower number of chronic drug prescriptions (Table 2) Goodness of fit for this model is adequate (chi-squared 5.6 with a $p=0.68$ ). The Cox and Snell pseudo- $\mathrm{R}^{2}$ computed was 0.26 .

Table 1. Differences Between Groups According to Successful Aging Status after the 2-Year Follow-Up

\begin{tabular}{|c|c|c|c|}
\hline & $\begin{array}{c}\text { Successful } \\
\text { aging }(\mathrm{n}=90)\end{array}$ & $\begin{array}{l}\text { Non successful } \\
\text { aging }(\mathrm{n}=56)\end{array}$ & $\mathrm{p}_{\text {value }}^{\mathrm{p}}$ \\
\hline Gender & & & 0.85 \\
\hline Male, $n(\%)$ & $40(44.4 \%)$ & $24(42.9 \%)$ & \\
\hline Female, $n(\%)$ & $50(55.6 \%)$ & $32(57.1 \%)$ & \\
\hline Marital status & & & 0.93 \\
\hline Married & $46(51.1 \%)$ & $27(48.2 \%)$ & \\
\hline Single & $4(4.4 \%)$ & $3(5.4 \%)$ & \\
\hline Widowed & $40(44.4 \%)$ & $26(46.4 \%)$ & \\
\hline Unmarried & $44(48.9 \%)$ & $29(51.8 \%)$ & 0.73 \\
\hline Studies & & & 0.02 \\
\hline Any or primary studies & $62(69 \%)$ & $48(85.7 \%)$ & \\
\hline Secondary or university studies & $28(31.1 \%)$ & $8(14.3 \%)$ & \\
\hline Living alone & $32(35.6 \%)$ & $18(32.1 \%)$ & 0.67 \\
\hline Barthel Index, mean \pm SD & $98.7 \pm 2.1$ & $98.3 \pm 2.3$ & 0.22 \\
\hline $\mathrm{MEC}$, mean $\pm \mathrm{SD}$ & $31.3 \pm 3$ & $29.5 \pm 2.6$ & 0.0001 \\
\hline $\mathrm{MNA}$, mean $\pm \mathrm{SD}$ & $26.8 \pm 2.1$ & $25.3 \pm 2.9$ & 0.001 \\
\hline Gijon questionnaire, mean $\pm S D$ & $9 \pm 2.4$ & $9.3 \pm 2.3$ & 0.49 \\
\hline Falls, mean $\pm S D$ & $0.26 \pm 0.5$ & $0.57 \pm 0.9$ & 0.01 \\
\hline Tinetti Gait Scale, mean \pm SD & $8.6 \pm 0.8$ & $7.8 \pm 1.6$ & 0.001 \\
\hline EuroQol-5D and EQ-VAS & $71 \pm 15$ & $63 \pm 21$ & 0,02 \\
\hline Charlson Co-morbidity Index, mean \pm SD & $0.91 \pm 1.2$ & $1.3 \pm 1.4$ & 0.11 \\
\hline Hypertension, $n(\%)$ & $67(74.4 \%)$ & $47(83.9 \%)$ & 0.17 \\
\hline Diabetes mellitus, $n(\%)$ & $9(10 \%)$ & $9(16 \%)$ & 0.41 \\
\hline Dyslipidemia, $n(\%)$ & $44(48.9 \%)$ & $33(58.9 \%)$ & 0.23 \\
\hline Previous stroke, $n(\%)$ & $10(11.1 \%)$ & $7(12.5 \%)$ & 0.80 \\
\hline Chronic obstructive lung disease, $n(\%)$ & $5(5.6 \%)$ & $3(5.4 \%)$ & 0.95 \\
\hline Heart failure, $n(\%)$ & $10(11 \%)$ & $5(9 \%)$ & 0.67 \\
\hline Atrial fibrillation, $n(\%)$ & $4(4.4 \%)$ & $12(21.4 \%)$ & 0.001 \\
\hline Ischemic cardiopathy, $n(\%)$ & $3(3.3 \%)$ & $4(7.1 \%)$ & 0.29 \\
\hline Cancer, $n(\%)$ & $13(14.4 \%)$ & $6(10.7 \%)$ & 0.51 \\
\hline Number of drugs taken, mean \pm SD & $4.6 \pm 2.6$ & $6.6 \pm 2.9$ & 0.0001 \\
\hline
\end{tabular}

SD, Standard deviation; MEC, Spanish version of the Mini-Mental State Examination. Score; MNA, Mini Nutritional Assessment score; EuroQol-5D and EQ-VAS, Quality of Life Test with the visual analog scale. 
Table 2. Odds Ratio of Variables in the Multiple Logistic Regression Analysis Model

\begin{tabular}{lccc}
\hline & $\begin{array}{c}\mathrm{p} \\
\text { value }\end{array}$ & $\begin{array}{c}\text { Odds } \\
\text { ratio }\end{array}$ & $\begin{array}{c}\text { 95\% confidence } \\
\text { interval }\end{array}$ \\
\hline $\begin{array}{l}\text { Secondary or } \\
\quad \text { university studies }\end{array}$ & 0.02 & 3.223 & $1.158-8.975$ \\
$\begin{array}{l}\text { Tinetti Gait Scale } \\
\text { MEC }\end{array}$ & 0.04 & 1.433 & $1.013-2.027$ \\
$\begin{array}{l}\text { Number of } \\
\quad \text { drugs taken }\end{array}$ & 0.01 & 1.204 & $1.046-1.386$ \\
& 0.001 & 0.768 & $0.655-0.899$ \\
\hline
\end{tabular}

MEC, Spanish version of the Mini-Mental State Examination.

\section{Discussion}

At 85 years old, people are very close to the maximum life bspan in developed countries. In the baseline assessment, including all the subjects of the NonaSatfeliu cohort, we found that half of the subjects who lived in the community had good physical and mental function. ${ }^{9}$ We have chosen these two aspects, because physical and cognitive dysfunction represent two of the most feared states among the elderly, because they can lead to dependency and social isolation. ${ }^{19}$ At 87 years, a considerable percentage $(61.6 \%)$ of the sample continued to age successfully. These very old people managed to stay alive, live in the community, and have good physical and mental function after what we can considerer a long follow-up with respect to the life expectancy of this population segment. In a previous study of nonagenarians (mean age 7 years older that the subjects included in this sample) in our area, we found a lower rate of maintenance of successful aging $(43.5 \%)^{8}$ than currently described.

After the application of the multivariate analysis, continuation of successful aging was significantly associated with a higher level of studies, better scores on a cognition test (MEC) and lower risk of falls (Tinetti gait scale), as well as a lower number of chronic drug prescriptions.

With regard to the importance of education, a high educational level has been previously reported as a predictive factor of "successful aging." ${ }^{2}$ We confirmed this association. Subjects born in 1924 would have been 12 years old at the outbreak of the Spanish Civil War in 1936, which could have contributed to a low level of education. However, in our study, $24 \%$ of participants had at least reached high school. This percentage is higher than that previously reported in the general Spanish population of the oldest old subjects ${ }^{20}$ and may have contributed to the subjects having reached 85 years. However, this cannot be inferred from the Octabaix study methodology. This association between education and successful aging needs to be contrasted in future studies.

Good cognitive function is an important part of the concept of successful aging. ${ }^{6,21}$ The preservation of cognitive abilities at the age of retirement can predict successful aging many years later. ${ }^{22}$ It is striking that even in the group of people evaluated in the present study with a narrow range of cognitive scores (all within normal limits), a few more points on the MEC can predict that a person will age successfully after 2 years. Some of the domains of the MMSE have proven to be more effective detecting losses. Specifically, poor performance on the MMSE orientation for time domain is as- sociated with a faster rate of decline in total MMSE scores over time, whereas good performance on the delayed recall domain, in addition to good performance on another domain, is associated with a slower rate of decline. ${ }^{23}$

Despite the importance of physical function, the use of the $\mathrm{BI}$ as a semiquantitative scale did not enable us to detect the predictive utility of any change in this factor, because all patients were included in the two BI categories of 95 or 100. The Tinetti gait scale measurement consists of seven components: Initiation of gait, step length and height (right and left foot), step symmetry, step continuity, path deviation, trunk stability, and walking stance. It seems logical that people with poor physical or cognitive function may report worse results on this test. Moreover, the Tinetti gait scale may be considered a test of lower limb performance, and it is also likely that it can evaluate the fragility of the subjects in some way. The association between functional and/or cognitive decline and falls is known. ${ }^{24}$ Therefore, the baseline evaluation showing that individuals of 85 years with better cognition and function had a lower risk of falls was an expected finding. ${ }^{9}$ A fall risk scale also serves to identify those who will maintain successful aging after 2 years of monitoring. The group of patients with successful aging had fewer falls during the year prior to the initial assessment, although this was not confirmed in the multivariate analysis.

The last factor associated with continued successful aging was fewer chronic drug prescriptions. In most cases, only essential drugs are prescribed. However, it is also known that increasing the number of drugs increases the risk of problems. Adverse side effects are a considerable cause of illness and death in elderly people. Thus, the appropriate, cost-effective use of medication is central to successful aging. ${ }^{25}$ Patient co-morbidity and the patient's control different needs are closely related to the number of drugs that are taken. Co-morbidity is the rule rather than an exception in the oldest subjects. At baseline in the Octabaix study evaluation, individuals with lower co-morbidity were associated with better aging. ${ }^{8}$ However, our opinion is similar to that previously reported ${ }^{21}$ : Chronic conditions do not necessarily preclude high levels of well-being in older individuals. Therefore, successful aging may coexist with diseases and functional limitations if compensatory psychological and/or social mechanisms are used. ${ }^{5}$

Among the remaining factors that lost their significance in the bivariate analysis are nutritional risk, atrial fibrillation, and quality of life assessment. The $\mathrm{MNA}^{13}$ is a simple tool used in clinical practice to measure nutritional status in elderly persons and to detect risk of malnutrition. As we found in the cross-sectional assessment 2 years ago, an association between reduced nutritional risk and better health outcome is not surprising. ${ }^{9}$ Here, the narrow margin in the MNA values of the study population at baseline, with an average score within the group of well-nourished subjects, may explain why the statistical differences are lost in the multivariate analysis. Atrial fibrillation is the commonest rhythm abnormality, and its occurrence increases with aging. It is often associated with high morbidity, including cognitive decline. ${ }^{26}$ Logically, atrial fibrillation could predict loss of good health status. However, the multivariate analysis did not confirm this factor. Finally, in the initial evaluation, we found that people defined as successful agers had better quality of life scores. Consequently, we were interested in 
checking whether this positive feeling of well-being was associated with maintaining successful aging at 2-year followup. An association was found in the bivariate analysis, but not in the multivariate analysis.

No gender differences existed in the current longitudinal study. In the previous nonagenarian study, we did find gender differences: At 2-year follow-up, male nonagenarians who were aging successfully were more likely to maintain this status than females. ${ }^{8}$

A recent interesting study classified the proportions of centenarians reaching 100 years as three profiles: (1) Survivors $(43 \%)$ of chronic diseases first experienced between 0 and 80 years of age; (2) delayers (36\%) with chronic diseases first experienced between 80 and 98 years of age; or (3) escapers $(17 \%)$ with chronic diseases only at 98 years of age or older. ${ }^{27}$ The follow-up of our cohort should let us know how many of them becoming "delayers or escapers" subjects and if a correlation exists between being classified as successful aging at 85 years old and being an escaper profile.

The strengths of this longitudinal Octabaix study include the use of a community-based sample of subjects of the same age. This sample provides a representative range of socioeconomic characteristics of older residents in our area, who were all registered with a general practice and all received a multiplicity of measures. However, we acknowledge that this strength might also constitute a weakness because it limits the generalization of the health survey findings to other populations. The study has several other limitations. Some measures that may affect the success of aging, including depression, were not evaluated. Another limitation of our study is that a subanalysis of MEC items was not performed to detect possible differences according to the areas of cognitive function (e.g., orientation, attention, calculation). Finally, the deleterious effect of certain events (hospitalizations, fractures, etc.), or the potential benefits of health promotion (immunizations, memory workshops, etc.) were recorded.

In conclusion, more than half of 87-year-old people in the population continued to age successfully, according to the quantitative definition chosen. In subjects aged 87 years, the factors associated with continued successful aging were a higher level of studies, better cognition scores, a lower risk of falls, and a lower number of chronic drug prescriptions.

\section{Author Disclosure Statement}

No competing financial interests exist.

\section{References}

1. Ferrer A, Formiga F, Ruiz D, Mascaró J, Olmedo C, Pujol R. Predictive items of functional decline and 2-year mortality in nonagenarians-the NonaSantfeliu study. Eur J Public Health 2008;18:406-409.

2. Rowe JW, Khan RL. Successful aging. Gerontologist 1997;37: 433-440.

3. Phelan EA, Larson EB. "Successful aging"-where next? J Am Geriatr Soc 2002;50:1306-1308.

4. Phelan EA, Anderson LA, LaCroix AZ, Larson EB. Older adults views of successful aging"-how do they compare with researchers' definitions? J Am Geriatr Soc 2004;52:211-216.

5. Young Y, Frick KD, Phelan EA. Can successful aging and chronic illness coexist in the same individual? A multidi- mensional concept of successful aging. J Am Med Dir Assoc 2009;10:87-92.

6. Fiocco AJ, Yaffe K. Defining successful aging: The importance of including cognitive function over time. Arch Neurol 2010;67:876-880.

7. Formiga F, Pujol R, Pérez-Castejon JM, Ferrer A, Henríquez E. Low comorbidity and male sex in nonagenarian community-dwelling people are associated with better functional and cognitive abilities: The NonaSantfeliu study. J Am Geriatr Soc 2005;53:1836-1837.

8. Formiga F, Ferrer A, Pérez-Castejon JM, Pujol R. Communitydwelling nondisabled nonagenarians: Two-year follow-up: the NonaSantfeliu Study. J Am Geriatr Soc 2007;55:801-803.

9. Formiga F, Ferrer A, Megido MJ, Chivite D, Badia T, Pujol R. Low co-morbidity, low levels of malnutrition, and low risk of falls in a community-dwelling sample of 85-year-olds are associated with successful aging: The Octabaix study. Rejuvenation Res 2011;14:309-314.

10. Ferrer A, Badia T, Formiga F, Gil A, Padrós G, Sarró M, Almeda J, Pujol R; Grupo de Estudio OCTABAIX. Ensayo aleatorizado de prevención de caídas y malnutrición en personas de 85 años en la comunidad. Estudio OCTABAIX. Rev Esp Geriatr Gerontol 2010;45:79-85.

11. Mahoney FI, Barthel DW. Functional evaluation: The Barthel Index. A simple index of independence useful in scoring improvement in the rehabilitation of the chronically ill. Md State Med J 1965;14:61-65.

12. Lobo A, Saz P, Marcos G, Día JL, De la Cámara C, Ventura T, Morales Asín F, Fernando Pascual L, Montañés JA, Aznar S. Revalidación y normalización del Mini-Examen Cognoscitivo (primera versión en castellano del Mini-mental Status Examination) en la población general geriátrica. Med Clin (Barc) 1999;112:767-774.

13. Guigoz Y, Vellas B, Garry PJ. Assessing the nutritional status of the elderly: the Mini Nutritional Assessment as part of the geriatric evaluation. Nutr Rev 1996;54 (Suppl);59-65.

14. Tinetti ME. Performance-oriented assessment of mobility problems in elderly patients. J Am Geriatr Soc 1986;34;119-126.

15. Buchner DM, Hornbrook MC, Kutner NG, Tinetti ME, Ory MG, Mulrow CD, Schechtman KB, Gerety MB, Fiatarone MA, Wolf SL, et al. et al Development of the Common Data Base for the FICSIT Trials. J Am Geriatr Soc 1993;41;297-308.

16. Alarcón MT, González JI. La escala sociofamiliar de Gijón, instrumento útil en el hospital general. Rev Esp Geriatr Gerontol 1998;33:178-180.

17. Herdman M, Badia X, Berra S. El EuroQol-5D: Una alternativa sencilla para medir calidad de vida relacionada con salud en atención primaria. Aten Primaria 2001;28:425-430

18. Charlson ME, Pompei P, Ales KL, MacKenzie CR.A new method of classifying prognostic comorbidity in longitudinal studies: Development and validation J Chronic Dis 1987;40:373-383.

19. Tabbarah M, Crimmins EM, Seeman TE. The relationship between cognitive and physical performance: MacArthur Studies of successful aging. J Gerontol Med Sci 2002;57:M228-M235.

20. Zunzunegui MV, Nunez O, Durban M, García de Yébenes MJ, Otero A. Decreasing prevalence of disability in activities of daily living, functional limitations and poor self-rated health: A 6-year follow-up study in Spain. Aging Clin Exp Res 2006;18:352-358.

21. Parslow RA, Lewis VJ, Nay R. Successful aging: development and testing of a multidimensional model using data from a large sample of older Australians. J Am Geriatr Soc 2011;59:2077-2083. 
22. Castro-Lionard $\mathrm{K}$, Thomas-Antérion $\mathrm{C}$, Crawford-Achour $\mathrm{E}$, Rouch I, Trombert-Paviot B, Barthélémy JC, Laurent B, Roche F, Gonthier R. Can maintaining cognitive function at 65 years old predict successful ageing 6 years later? The PROOF study. Age Ageing 2011;40:259-265.

23. Guerrero-Berroa E, Luo X, Schmeidler J, Rapp MA, Dahlman K, Grossman HT, Haroutunian V, Beeri MS. The MMSE orientation for time domain is a strong predictor of subsequent cognitive decline in the elderly. Int J Geriatr Psychiatry 2009;24:1429-1437.

24. Formiga F, Navarro M, Duaso E, Chivite D, Ruiz D, PerezCastejon JM, Lopez-Soto A, Pujol R. Factors associated with hip fracture-related falls among patients with a history of recurrent falling. Bone 2008;43:941-944.

25. Murray MD, Callahan CM. Improving medication use for older adults: An integrated research agenda. Ann Intern Med 2003;139:425-429.

26. Formiga F, Ferrer A, Mimbrera D, Badia T, Fernández C, Pujol R; Grupo de Estudio Octabaix. High rate of anticoagulation therapy in oldest old subjects with atrial fibrillation: The Octabaix study. J Am Med Dir Assoc 2012;13:8-10.
27. Arnold J, Dai J, Nahapetyan L, Arte A, Johnson MA, Hausman D, Rodgers WL, Hensley R, Martin P, Macdonald M, Davey A, Siegler IC, Jazwinski SM, Poon LW. Predicting successful aging in a population-based sample of Georgia centenarians. Curr Gerontol Geriatr Res 2010;2010:989315.

Address correspondence to: Francesc Formiga Geriatric Unit, Internal Medicine Service Hospital Universitari de Bellvitge L'Hospitalet de Llobregat 08907

Barcelona Spain

E-mail: fformiga@bellvitgehospital.cat

Received: April 17, 2012 Accepted: June 28, 2012 